\title{
Gray zone lymphoma: chromosomal aberrations with immunophenotypic and clinical correlations
}

Franziska C Eberle E, $^{1, *}$, Itziar Salaverria ${ }^{3, *}$, Christian Steidl ${ }^{4, *}$, Thomas A Summers $\mathrm{Jr}^{1}$, Stefania Pittaluga ${ }^{1}$, Susana Ben Neriah ${ }^{4}$, Jaime Rodriguez-Canales ${ }^{1}$, Liqiang Xi ${ }^{1}$, Kris Ylaya ${ }^{1}$, David Liewehr ${ }^{5}$, Kieron Dunleavy ${ }^{6}$, Wyndham H Wilson ${ }^{6}$, Stephen M Hewitt ${ }^{1}$, Mark Raffeld ${ }^{1}$, Randy D Gascoyne ${ }^{4}$, Reiner Siebert ${ }^{3}$ and Elaine S Jaffe ${ }^{1}$

${ }^{1}$ Laboratory of Pathology, Center for Cancer Research, National Cancer Institute, National Institutes of Health, Bethesda, MD, USA; ${ }^{2}$ Department of Dermatology, Eberhard Karls University Tuebingen, Tuebingen, Germany; ${ }^{3}$ Department of Tumor Genetics, Institute of Human Genetics, Christian-Albrechts-University Kiel and University Hospital Schleswig-Holstein, Campus Kiel, Germany; ${ }^{4}$ Department of Pathology and Laboratory Medicine, Centre for Lymphoid Cancers and the Centre for Translational and Applied Genomics (CTAG), Vancouver, BC, Canada; ${ }^{5}$ Biostatistics and Data Management Section, Office of the Clinical Director, Center for Cancer Research, National Cancer Institute, National Institutes of Health, Bethesda, MD, USA and ${ }^{6}$ Metabolism Branch, Center for Cancer Research, National Cancer Institute, National Institutes of Health, Bethesda, MD, USA

The term gray zone lymphoma has been applied to tumors that demonstrate transitional morphologic and immunophenotypic features between classical Hodgkin's lymphoma and diffuse large B-cell lymphoma, especially primary mediastinal large B-cell lymphoma. Histopathological and genetic data are limited for these unusual cases. We analyzed cases of gray zone lymphoma $(n=27)$, mediastinal composite lymphoma $(n=3)$ and mediastinal synchronous/metachronous lymphoma $(n=3)$ by morphology, immunophenotyping and fluorescence in situ hybridization. Mediastinal involvement was assured in $24 / 33$ patients $(73 \%)$. The patient cohort showed a male predominance (M:F ratio; 20:13) and a median age of 32 years (range, 16-91 years). Patients with mediastinal disease were significantly younger (median age: 29.5 years) than patients presenting without evident mediastinal disease (median age: 55 years). Gains including amplifications in 2p16.1 (REL/BCL11A locus) were observed in $33 \%$ of all patients, whereas alterations affecting the JAK2/PDL2 locus in 9p24.1 were present in 55\%. Further studies revealed rearrangement of the CIITA locus at 16 p13.13 in $8 / 30$ cases $(27 \%)$ and $7 / 26$ cases $(27 \%)$ demonstrated gains of $8 \mathrm{q} 24$ (MYC). Genetic aberrations involving 2p16.1, 9p24.1 and 8q24 showed a higher incidence in cases with evident mediastinal involvement. However, this was not statistically significant when compared with cases without known mediastinal involvement. Twelve of the $\mathbf{2 7}$ cases of gray zone lymphoma were morphologically more reminiscent of classical Hodgkin's lymphoma, whereas the other gray zone lymphomas presented with morphological features more closely resembling large B-cell lymphoma. Both morphological groups of gray zone lymphoma were similarly positive for Cyclin E (75 and 93\%) and p63 (50 and 53\%, respectively) expression. These findings further support a close relationship between gray zone lymphoma, classical Hodgkin's lymphoma and primary mediastinal large B-cell lymphoma, and suggest that some cases of gray zone lymphoma without mediastinal disease may share similar genetic alterations.

Modern Pathology (2011) 24, 1586-1597; doi:10.1038/modpathol.2011.116; published online 5 August 2011

Keywords: chromosomal aberrations; fluorescence in situ hybridization (FISH); gray zone lymphoma; Hodgkin lymphoma; immunohistochemistry; large B-cell lymphoma; mediastinal lymphoma; oncogenes

Correspondence: Dr ES Jaffe, MD, Hematopathology Section, Laboratory of Pathology, National Cancer Institute, National Institutes of Health, Building 10, Room 2B42 MSC-1500, Bethesda, MD 20892, USA.

E-mail: ejaffe@mail.nih.gov

*These authors contributed equally to this work.

Received 28 February 2011; revised 31 May 2011; accepted 31 May 2011; published online 5 August 2011
Primary mediastinal large B-cell lymphoma and classical Hodgkin's lymphoma, nodular sclerosis subtype, share many common clinical and biological characteristics, and have been reported sequentially in the same patient and as composite lymphomas, in the same anatomic site. ${ }^{1-6}$ Gene expression profiling studies of primary mediastinal large B-cell 
lymphoma and classical Hodgkin's lymphoma, and nodular sclerosis subtype showed that the profile of primary mediastinal large B-cell lymphoma differs from that of non-mediastinal diffuse large B-cell lymphoma but shows similarity to that of classical Hodgkin's lymphoma. ${ }^{7-9}$ Subsequently, TraverseGlehen et $a l^{6}$ identified a variant of lymphoma, termed mediastinal gray zone lymphoma, that had overlapping morphologic and immunophenotypic features between primary mediastinal large B-cell lymphoma and the nodular sclerosis subtype of classical Hodgkin's lymphoma, further supporting a close relationship between these diseases. Although most gray zone lymphomas are associated with mediastinal disease, similar cases have also been reported in peripheral lymph node groups without mediastinal involvement. The $4^{\text {th }}$ Edition of the World Health Organization Classification of Tumors of the Hematopoietic and Lymphoid Tissues included these so-called gray zone lymphomas presenting with or without mediastinal involvement as 'B-cell lymphoma, unclassifiable, with features intermediate between diffuse large B-cell lymphoma and classical Hodgkin's lymphoma'. ${ }^{10}$ A number of common genetic aberrations have been reported in primary mediastinal large B-cell lymphoma and classical Hodgkin's lymphoma, further underscoring their close relationship. Classical Hodgkin's lymphomas show frequent gains of regions on chromosome $2 p, 9 p, 16 p$ and $8 q$ and similar aberrations were also identified in primary mediastinal large B-cell lymphoma. ${ }^{11-23}$ In this study, we characterized 27 cases of gray zone lymphoma, 3 cases of mediastinal composite lymphoma and 3 cases of mediastinal synchronous/metachronous lymphoma by interphase cytogenetics using fluorescence in situ hybridization to investigate the presence of chromosomal aberrations previously identified in the parent entities of primary mediastinal large B-cell lymphoma and the nodular sclerosis subtype of classical Hodgkin's lymphoma. We compared cases with and without evident mediastinal involvement, to determine if they were similar at the genetic level. Finally, we investigated morphological and immunophenotypic features to identify potential associations with the genetic alterations, or factors that would link gray zone lymphomas more closely to primary mediastinal large B-cell lymphoma or classical Hodgkin's lymphoma, respectively.

\section{Materials and methods}

\section{Case Selection}

The following cases of lymphoma were eligible for this study: (1) B-cell lymphoma, unclassifiable with features intermediate between classical Hodgkin's lymphoma and diffuse large B-cell lymphoma (with or without mediastinal involvement), (2) mediastinal composite lymphoma with both classical Hodgkin's lymphoma and primary mediastinal large
B-cell lymphoma components in the same biopsy, and (3) mediastinal synchronous or metachronous lymphoma with synchronous or metachronous occurrences of primary mediastinal large B-cell lymphoma and classical Hodgkin's lymphoma in the same patient. All cases were determined to be negative for Epstein-Barr virus by EpsteinBarr-virus-encoded RNA in situ hybridization, as Epstein-Barr-virus-positive large B-cell lymphomas, although they might show some overlapping features with classical Hodgkin's lymphoma, are not felt to be part of the same entity. ${ }^{24}$ Thirty-three cases met these criteria, and formalin-fixed paraffinembedded tissue specimens were retrieved from the tissue archives of the National Cancer Institute Laboratory of Pathology. Thirteen cases were previously reported. ${ }^{6,25}$ Clinical data regarding extent of disease and presence of mediastinal involvement were collected from the referring physicians. The study was approved by the Institutional Review Board of the National Cancer Institute. Cases were reviewed by SP and ESJ and the final histopathologic diagnoses were reported according to World Health Organization criteria. ${ }^{10}$

\section{Tissue Microarray}

The most representative tumor areas of 27 cases were carefully selected based on the matched hematoxylin \& eosin (H\&E)-stained slides and marked directly on the donor block. Two tissue cores (diameter $1.0 \mathrm{~mm}$ ) were transferred from the selected region of each donor block and arrayed into the recipient block using a manual tissue microarrayer (Beecher Instruments, Silver Spring, MD, USA). The final recipient block was incubated and tempered at $37^{\circ} \mathrm{C}$ overnight. Following the tissue microarray construction, $5 \mu \mathrm{m}$ sections were cut with a microtome (Leica RM2255, Bannockburn, IL, USA) on positively charged slides (Fisherbrand, Superfrost/Plus, Pittsburgh, PA, USA), allowed to dry at room temperature and heated to $65^{\circ} \mathrm{C}$ for 30 min to melt the paraffin. A tissue microarray section was stained with H\&E for quality assurance and confirmation of diagnostic elements on the tissue microarray. An additional seven biopsies from six cases that were not included on the tissue microarray (nos. 14, 15, 25, 26, 27, 32) were examined by fluorescence in situ hybridization and immunohistochemistry utilizing unstained sections.

\section{Morphologic and Immunophenotypic Studies}

The morphologic features of the selected cases were assessed on H\&E-stained sections (FCE, TAS, SP and ESJ). Immunophenotypic analyses were performed by the avidin-biotin-peroxidase complex method using an automated immunostainer (Ventana-Biotech, Tucson, AZ, USA). Tissue sections were stained with antibodies directed against CD20 (L26; Dako, Carpinteria, 
CA, USA), polyclonal CD3 (Dako), CD30 (1G12; Novocastra, Newcastle Upon Tyne, England), CD15 (MMA; Becton Dickinson, Franklin Lakes, NJ, USA), CD79a (JCB117; Dako), BOB.1 (OBF.1; Santa Cruz Biotechnology, Santa Cruz, CA, USA), Oct-2 (C-20; Santa Cruz Biotechnology), p63 (4A4; Cell Marque Corporation, Rocklin, CA, USA), Cyclin E (Santa Cruz Biotechnology) and HLA-DR (TAL.1B5; Dako).

The original diagnosis of gray zone lymphoma was based on immunophenotypic studies performed at the time of diagnosis with immunostains for CD20, CD30, CD15, CD79a, Oct-2, Bob.1 and CD3. Some cases with an incomplete panel were rescored on the TMA. In addition, results of immunostains performed on the TMA and on the original sections were compared, with consistent results between the two platforms. Stains for p63 and Cyclin E were performed on the TMA in most instances; single unstained sections were stained in six cases without available blocks for the TMA. An antibody was scored as positive if at least $30 \%$ of tumor cells demonstrated positivity with the expected pattern, nuclear, cytoplasmic or membranous. However, CD20 was scored as positive only if the majority of the tumor cells showed strong staining of uniform intensity. HLA-DR scoring was performed by estimation of positive tumor cells (0, negative; $1,1-25 \%$ positive tumor cells; 2, 26-50\% positive tumor cells; 3, 51-75\% positive tumor cells; 4, 76-100\% positive tumor cells).

\section{Molecular Studies}

DNA extraction was performed on formalin-fixed paraffin-embedded tissue with the QIAcube extraction platform using the QIAamp DNA FFPE Tissue Kit (QIAGEN, Valencia, CA, USA). PCR was performed using consensus primers directed to $\mathrm{V}_{\mathrm{H}}$ framework (FR) III and joining region $\left(\mathrm{J}_{\mathrm{H}}\right)$ of the immunoglobulin heavy chain gene (FRIII-IGH PCR) and to $\mathrm{V}_{\mathrm{H}} \mathrm{FR}$ region II and the joining region (FRIIIGH PCR), according to the method of Ramasamy et $a .^{26}$ Testing for the $I G K$ locus was additionally performed using the BIOMED-2 primer set described by van Dongen et $a l^{27}$ and supplied by In Vivo Scribe Technologies (IGK Gene Clonality Assay-ABI Fluorescence Detection). These reactions interrogate rearrangements involving the $\mathrm{V} \kappa$ loci and $\mathrm{J} \kappa$ (tube $\mathrm{A}$ ), the $\mathrm{V} \kappa$ locus and the $\kappa \mathrm{DE}$ locus (tube $\mathrm{B}$ ), and the $\kappa$-intron RSS locus and the $\kappa \mathrm{DE}$ locus (tube B). The products from all reactions were separated by capillary electrophoresis on an ABI 3130xl Genetic Analyzer (Applied Biosystems, Carlsbad, CA, USA) and the electropherograms were analyzed using GeneMapper software version 4.0 (ABI).

\section{Fluorescence In Situ Hybridization}

Interphase FISH for detection of chromosomal imbalances or rearrangements involving $M Y C$ (8q24), REL/BCL11A (2p16), JAK2/PDL2 (9p24) and CIITA (16p13.13) was performed according to previously published protocols using FISH probes outlined in Supplementary Table S1. ${ }^{23,28}$ Gains were considered when more than two signals per probe were observed in a significant percentage of cells (defined as $\geq 10 \%$ for $M Y C, R E L / B C L 11 A$, $J A K 2 / P D L 2$ break apart probes and $\geq 5 \%$ for CIITA probe). Amplifications were defined as more than four signals per probe or the presence of a signal cloud. Cases were independently scored by IS, CS and SBN. Some loci were hybridized and scored in two laboratories (JAK2/PDL2), and in the event of discordance, the sections were rescored and the results reconciled. Results were not corrected for ploidy as data to estimate ploidy levels were too scarce based on the few FISH probes applied.

\section{Statistical Analysis}

Tests for general associations between categorical variables were performed using Fisher's exact test for $2 \times 2$ tables and Mehta's version of Fisher's exact test for $2 \times \mathrm{C}$ tables. Distributions of continuous variables were compared between two categories using a Wilcoxon rank-sum test.

\section{Results}

\section{Clinical Features}

A total of 33 cases were analyzed: 27 cases of gray zone lymphoma, 3 cases of mediastinal composite lymphoma and 3 cases of mediastinal synchronous/ metachronous lymphoma (Table 1). The series showed a male predominance with a male/female ratio of $20: 13$ and a median age of 32 years at presentation (range, 16-91 years). A male predominance was evident in patients with composite lymphoma; patients with synchronous/metachronous lymphoma had a male/female ratio of 2:1. Mediastinal involvement was assured in 24 of 33 patients $(73 \%)$, whereas mediastinal involvement could not be documented in the remaining patients. Significant age differences were observed between patients with and without mediastinal disease. Patients with mediastinal involvement were diagnosed at a median age of 29.5 years (range, 16-51 years), whereas patients without evident mediastinal disease had a median age of 55 years (range, 24-91 years; $P=0.017$, Wilcoxon rank-sum test) (Table 2). No significant differences concerning gender distribution could be observed between the two groups (Table 2).

Among patients with mediastinal disease, the most common biopsy sites included the mediastinum, cervical/neck lymph nodes and supraclavicular lymph nodes. Two extranodal biopsies, one of the lungs (no. 24) and another of the 
Table 1 Clinical, histological and immunophenotypic characteristics of included cases

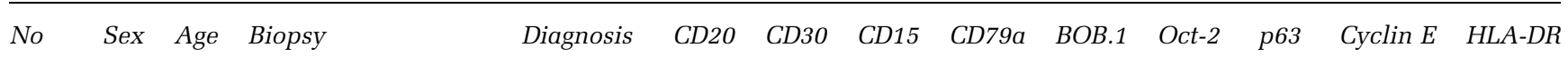

Gray zone lymphoma without evident mediastinal disease

$\begin{array}{lcrll}1 & \text { M } & 55 & \text { Neck LN } & \text { GZL } \\ 2^{\text {a }} & \text { F } & 67 & \text { Neck mass } & \text { GZL } \\ 3 & \text { F } & 58 & \text { Inguinal LN } & \text { GZL } \\ 4 & \text { M } & 26 & \text { Neck mass } & \text { GZL } \\ 5 & \text { F } & 91 & \text { Axillary LN } & \text { GZL } \\ 6 & \text { F } & 24 & \text { Cervical LN } & \text { GZL } \\ 7 & \text { F } & 48 & \text { Axillary LN } & \text { GZL } \\ 8 & \text { F } & 25 & \text { Neck LN } & \text { GZL } \\ 9 & \text { M } & 85 & \text { Axillary mass } & \text { GZL }\end{array}$

Gray zone lymphoma with mediastinal disease

\begin{tabular}{|c|c|c|c|c|c|c|c|c|c|c|c|c|c|}
\hline 10 & $\mathrm{M}$ & 32 & Neck mass ${ }^{\mathrm{b}}$ & GZL & + & + & + & + & + & + & + & + & 0 \\
\hline $11^{\mathrm{c}}$ & $\mathrm{F}$ & 38 & Mediastinal mass ${ }^{\mathrm{b}}$ & GZL & + & + & + & - & + & + & + & + & 4 \\
\hline $12^{\mathrm{a}}$ & M & 16 & Neck $\mathrm{LN}^{\mathrm{b}}$ & GZL & + & + & - & - & + & + & - & + & 4 \\
\hline 13 & M & 16 & Chest wall mass ${ }^{\mathrm{b}}$ & GZL & + & + & + & + & - & - & - & - & 4 \\
\hline 14 & $\mathrm{M}$ & 43 & Cervical LN ${ }^{\mathrm{b}}$ & GZL & + & + & - & + & + & + & + & + & 4 \\
\hline 15 & M & 26 & Mediastinal mass ${ }^{\mathrm{b}}$ & GZL & - & + & + & - & - & + & + & + & 2 \\
\hline 16 & M & 17 & Mediastinal mass ${ }^{\mathrm{b}}$ & GZL & + & + & + & + & + & + & - & + & 4 \\
\hline $17^{\mathrm{c}}$ & $\mathrm{M}$ & 28 & Mediastinal mass ${ }^{b}$ & GZL & + & + & + & + & + & + & + & + & 2 \\
\hline 18 & $\mathrm{~F}$ & 29 & Mediastinal mass ${ }^{\mathrm{b}}$ & GZL & + & + & + & - & + & + & - & + & 4 \\
\hline $19^{\mathrm{a}}$ & $\mathrm{M}$ & 43 & Neck LN ${ }^{\mathrm{b}}$ & GZL & + & + & + & + & + & + & + & + & 4 \\
\hline 20 & $\mathrm{~F}$ & 27 & Mediastinal mass ${ }^{\mathrm{b}}$ & GZL & + & + & + & + & + & + & + & + & 1 \\
\hline 21 & $\mathrm{~F}$ & 47 & Cervical LN ${ }^{\mathrm{b}}$ & GZL & + & + & + & - & + & + & + & + & 4 \\
\hline $22^{\mathrm{a}}$ & M & 37 & Mediastinal $\mathrm{LN}^{\mathrm{b}}$ & GZL & - & + & + & + & + & - & - & + & 1 \\
\hline 23 & $\mathrm{M}$ & 51 & Pericardial mass ${ }^{\mathrm{b}}$ & GZL & - & + & - & + & + & + & - & + & 1 \\
\hline 24 & $\mathrm{~F}$ & 30 & Lung $^{\mathrm{b}}$ & GZL & - & + & - & + & + & + & + & + & 0 \\
\hline $25^{\mathrm{c}}$ & $\mathrm{F}$ & 21 & Mediastinal mass b & GZL & + & + & + & - & nd & nd & + & + & 4 \\
\hline $26^{\mathrm{c}}$ & $\mathrm{M}$ & 32 & Mediastinal mass ${ }^{b}$ & GZL & + & + & + & - & nd & nd & + & + & 4 \\
\hline 27 & M & 20 & Mediastinal mass ${ }^{\mathrm{b}}$ & GZL & + & + & + & + & - & + & - & + & 4 \\
\hline . & & 110 & te lympnoma & & & & & & & & & & \\
\hline $28^{\mathrm{d}}$ & M & 41 & Supraclavicular $\mathrm{LN}^{\mathrm{b}}$ & CHL/PMBL & $-1+$ & $+1-$ & $+1-$ & $-/ \mathrm{nd}$ & $+/ \mathrm{nd}$ & $+/ \mathrm{nd}$ & $+/ \mathrm{nd}$ & $+/ \mathrm{nd}$ & no \\
\hline $29^{\mathrm{d}}$ & $\mathrm{M}$ & 46 & Mediastinal mass ${ }^{\mathrm{b}}$ & CHL/PMBL & $-1+$ & $+/+$ & $+1-$ & $+/ \mathrm{nd}$ & $+/ \mathrm{nd}$ & $-/ \mathrm{nd}$ & $-/ \mathrm{nd}$ & $-/ \mathrm{nd}$ & 4 \\
\hline $30^{\mathrm{a}}$ & $\mathrm{M}$ & 23 & Neck LN ${ }^{\mathrm{b}}$ & CHL/PMBL & $+/+$ & $+1-$ & $+1-$ & $+/ \mathrm{nd}$ & $+/ \mathrm{nd}$ & $+/ \mathrm{nd}$ & $-/ \mathrm{nd}$ & $+/ \mathrm{nd}$ & \\
\hline
\end{tabular}

Mediastinal synchronous/metachronous lymphoma

\begin{tabular}{|c|c|c|c|c|c|c|c|c|c|c|c|c|c|}
\hline \multirow[t]{2}{*}{$31^{\mathrm{d}}$} & M & 25 & Supraclavicular $\mathrm{LN}^{\mathrm{b}}$ & $\mathrm{CHL}^{\mathrm{e}}$ & - & + & - & nd & nd & nd & nd & nd & nd \\
\hline & & & Intestine & $\mathrm{PMBL}^{\mathrm{e}}$ & + & nc & - & + & + & + & + & + & 1 \\
\hline \multirow[t]{2}{*}{32} & $\mathrm{~F}$ & 22 & Neck LN ${ }^{\mathrm{b}}$ & $\mathrm{CHL}^{\mathrm{e}}$ & - & + & + & - & + & + & - & - & 2 \\
\hline & & & Axillary LN & $\mathrm{PMBL}^{\mathrm{e}}$ & + & + & + & + & + & + & + & + & 4 \\
\hline \multirow[t]{2}{*}{$33^{\mathrm{c}}$} & $\mathrm{M}$ & 43 & Mediastinal mass $^{\mathrm{b}}$ & $\mathrm{PMBL}^{\mathrm{f}}$ & + & + & nd & nd & nd & nd & nd & nd & nd \\
\hline & & & Supraclavicular LN & $\mathrm{CHL}^{\mathrm{f}}$ & - & + & + & - & + & + & - & + & 4 \\
\hline
\end{tabular}

Abbreviations: CHL, classical Hodgkin's lymphoma; F, female; GZL, gray zone lymphoma; LN, lymph node; M, male; nc, non contributory; No, case number; nd, not done; PMBL, primary mediastinal large B-cell lymphoma; +, positive; -, negative.

${ }^{\mathrm{a}}$ Patient was part of the study by Eberle et al. ${ }^{25}$

${ }^{\mathrm{b}}$ Patient has mediastinal involvement.

${ }^{\mathrm{C}}$ Patient was part of the study by Traverse-Glehen et $a .^{6}$

${ }^{\mathrm{d}}$ Patient was part of the study by Traverse-Glehen et al ${ }^{6}$ and Eberle et al. ${ }^{25}$

${ }^{\mathrm{e}} \mathrm{CHL}$ with relapse as PMBL.

${ }^{\mathrm{f}} \mathrm{PMBL}$ with relapse as CHL.

HLA-DR scoring: 0 , negative; $1,1-25 \%$ positive tumor cells; $2,26-50 \%$ positive tumor cells; $3,51-75 \%$ positive tumor cells; 4 , 76-100\% positive tumor cells.

intestine (no. 31), were also included in this study (Table 1). Although these two biopsies were extranodal and non-mediastinal, both patients presented with a mediastinal mass. The most common biopsy sites in patients without evident mediastinal disease were cervical/neck lymph nodes and axillary lymph nodes. A summary of the clinical findings of all patients is presented in Table 1.

\section{Morphological and Immunophenotypic Features}

Gray zone lymphoma is defined as a lymphoma showing histologic and immunophenotypic features indeterminate between diffuse large B-cell lymphoma and classical Hodgkin's lymphoma. There is often asynchrony between morphology and immunophenotype. In twelve of our gray zone lymphoma cases the overall morphologic features 
Table 2 Association of the presence of mediastinal disease with the patient age, gender and genetic aberrations

\begin{tabular}{|c|c|c|c|}
\hline & $\begin{array}{l}\text { No evident } \\
\text { mediastinal } \\
\text { disease }\end{array}$ & $\begin{array}{l}\text { Mediastinal } \\
\text { disease }\end{array}$ & $\mathrm{P}$ \\
\hline \multicolumn{4}{|l|}{ Age } \\
\hline $\begin{array}{l}\text { Median } \\
\text { (Range) }\end{array}$ & $\begin{array}{c}\mathbf{5 5} \text { years } \\
(24-91 \text { years })\end{array}$ & $\begin{array}{l}29.5 \text { years } \\
(16-51 \text { years })\end{array}$ & $0.017^{\mathrm{a}}$ \\
\hline \multicolumn{4}{|l|}{ Gender } \\
\hline Male:female & $3: 6$ & $17: 7$ & $0.11^{\mathrm{b}}$ \\
\hline $\begin{array}{l}\text { FISH analysis } \\
\text { 2p16.1 (BCL11, REL) } \\
\text { gain/amplification }\end{array}$ & $\mathbf{2 5} \%(2 / 8)$ & $\mathbf{3 6} \%(8 / 22)$ & $0.68^{\mathrm{b}}$ \\
\hline $\mathbf{8 q 2 4}(M Y C)$ gain & $17 \%(1 / 6)$ & $30 \%(6 / 20)$ & $1.0^{\mathrm{b}}$ \\
\hline $\begin{array}{l}\text { 9p24.1 (JAK2, PDL2) } \\
\text { gain/amplification }\end{array}$ & $\mathbf{3 8 \%}(3 / 8)$ & $\mathbf{6 1} \%(14 / 23)$ & $0.41^{\mathrm{b}}$ \\
\hline $\begin{array}{l}\text { 16p13.13 (CIITA) gain/ } \\
\text { amplification/break }\end{array}$ & $\mathbf{4 4} \%(4 / 9)$ & $33 \%(7 / 21)$ & $0.69^{\mathrm{b}}$ \\
\hline
\end{tabular}

${ }^{\mathrm{a}}$ Wilcoxon rank-sum test.

${ }^{\mathrm{b}}$ Fisher's exact test.

Table 3 Association of immunophenotypic features and chromosomal aberrations in gray zone lymphoma with Hodgkin-like or large-B-cell-lymphoma-like morphology

\begin{tabular}{llr}
\hline & $\begin{array}{l}\text { Hodgkin-like } \\
\text { morphology, } \%\end{array}$ & $\begin{array}{l}\text { Large-B-cell- } \\
\text { lymhoma-like } \\
\text { morphology, } \%\end{array}$ \\
\hline $\begin{array}{l}\text { Immunohistochemistry } \\
\text { CD20 }\end{array}$ & $\mathbf{8 3}(10 / 12)$ & $\mathbf{7 3}(11 / 15)$ \\
CD30 & $\mathbf{9 2}(11 / 12)$ & $\mathbf{1 0 0}(15 / 15)$ \\
CD15 & $\mathbf{5 8}(7 / 12)$ & $\mathbf{8 0}(12 / 15)$ \\
CD79a & $\mathbf{7 5}(9 / 12)$ & $\mathbf{6 7}(10 / 15)$ \\
BOB.1 & $\mathbf{8 3}(10 / 12)$ & $\mathbf{8 5}(11 / 13)$ \\
Oct-2 & $\mathbf{5 0}(6 / 12)$ & $\mathbf{8 5}(11 / 13)$ \\
p63 & $\mathbf{7 5}(9 / 12)$ & $\mathbf{5 3}(8 / 15)$ \\
Cyclin E & & $\mathbf{9 3}(14 / 15)$ \\
FISH analysis & $\mathbf{4 2}(5 / 12)$ & $\mathbf{2 9}(4 / 14)$ \\
2p16.1 (BCL11, REL) & & \\
gain/amplification & $\mathbf{2 0}(2 / 10)$ & $\mathbf{3 1}(4 / 13)$ \\
$\mathbf{8 q 2 4}$ (MYC) gain & $\mathbf{4 2}(5 / 12)$ & $\mathbf{5 7}(8 / 14)$ \\
9p24.1 (JAK2, PDL2) & & $\mathbf{3 6}(5 / 14)$ \\
gain/amplification & $\mathbf{4 2}(5 / 12)$ & \\
16p13.13 (CIITA) gain/ & & \\
amplification/break & & \\
\hline
\end{tabular}

on H\&E-stained sections more closely resembled classical Hodgkin's lymphoma. These tumors had cells resembling Hodgkin-Reed-Sternberg cells and lacunar variants in an inflammatory background of eosinophils and neutrophils, and sometimes focal necrosis. The tumor cells of most of these cases showed strong positive staining for CD20 (10/12) and CD30 (11/12). CD15 was positive in 7/12 cases (58\%). Nine cases $(75 \%)$ were positive for CD79a. BOB.1 and Oct- 2 were positive in 10/12 cases (83\%) and $11 / 12$ cases $(92 \%)$, respectively. Positivity for p63 and Cyclin E was observed in 50\% (6/12) and $75 \%(9 / 12)$ of the cases, respectively. (Tables 1 and 3, Figure 1). The remaining 15 cases of gray zone lymphoma demonstrated morphologic features more characteristic of large B-cell lymphoma. They exhibited a monomorphous infiltrate of large cells with sparse inflammatory background. In some cases sheets of large cells resembling mononuclear Hodgkin-Reed-Sternberg cells were focally observed. Immunohistochemical studies showed consistent positivity for CD30 in all cases and positivity for CD15 in most of the cases (12/15 cases, 80\%). CD20 was strongly expressed in $11 / 15$ cases $(73 \%)$, whereas CD20 was negative in 4 . One of the CD20negative cases was also negative for CD79a. CD79a was present in 10/15 cases (67\%). BOB.1 and Oct-2 were positive in the majority of cases, $11 / 13$ cases $(85 \%)$ and $11 / 13$ cases $(85 \%)$, respectively. Positive results for Cyclin E were found in all but one case (93\%), and p63 was positive in more than half of the cases (8/15) (Tables 1 and 3, Figure 1).

Three cases of mediastinal composite lymphoma (no. 28-30) were included, and represented cases in which two distinct histologic components, a Hodgkin and a large B-cell lymphoma component, were present in the same biopsy. ${ }^{6}$ As expected, the Hodgkin component was uniformly positive for CD30 and CD15, but CD20 was negative in two cases (no. 28 and 29). Accordingly, the large B-cell component was CD20 positive and CD15 negative in all three cases, whereas CD30 was negative in two cases (no. 28 and 30) (Table 1). In the composite lymphomas only the Hodgkin component of each biopsy could be analyzed for CD79a, BOB.1, Oct-2, Cyclin E and p63 as the other component was lost in deeper sections. The Hodgkin component of the composite lymphomas was positive for BOB.1 in all cases, positive for CD79a, Oct-2 and Cyclin E in $2 / 3$ cases, and positive for p63 in 1/3 cases.

Mediastinal synchronous/metachronous lymphomas are defined as exhibiting large B-cell lymphoma and classical Hodgkin's lymphoma in different biopsies in the same patient (cases no. 31-33). ${ }^{6}$ Two presented as Hodgkin's lymphoma first, followed by the diagnosis of primary mediastinal large B-cell lymphoma 1 month later (no. 31) and 6 months later (no. 32), respectively. The third case was a primary mediastinal large B-cell lymphoma that relapsed as Hodgkin's lymphoma 1 year later (no. 33). Similar to mediastinal composite lymphomas, the morphological and immunophenotypic features of mediastinal synchronous/metachronous lymphomas showed characteristic features of classical Hodgkin's lymphoma and large B-cell lymphoma in the majority of cases (Table 1).

\section{Molecular Studies}

One case of mediastinal metachronous lymphoma (no. 32) with sufficient material from both biopsies 
(classical Hodgkin's lymphoma and primary mediastinal large B-cell lymphoma) was analyzed for a clonal relationship between the two lymphomas.
Both reactions (FRIII, FRII) for the IGH locus were negative for a clonal process in both biopsies, whereas reactions interrogating the IGK locus
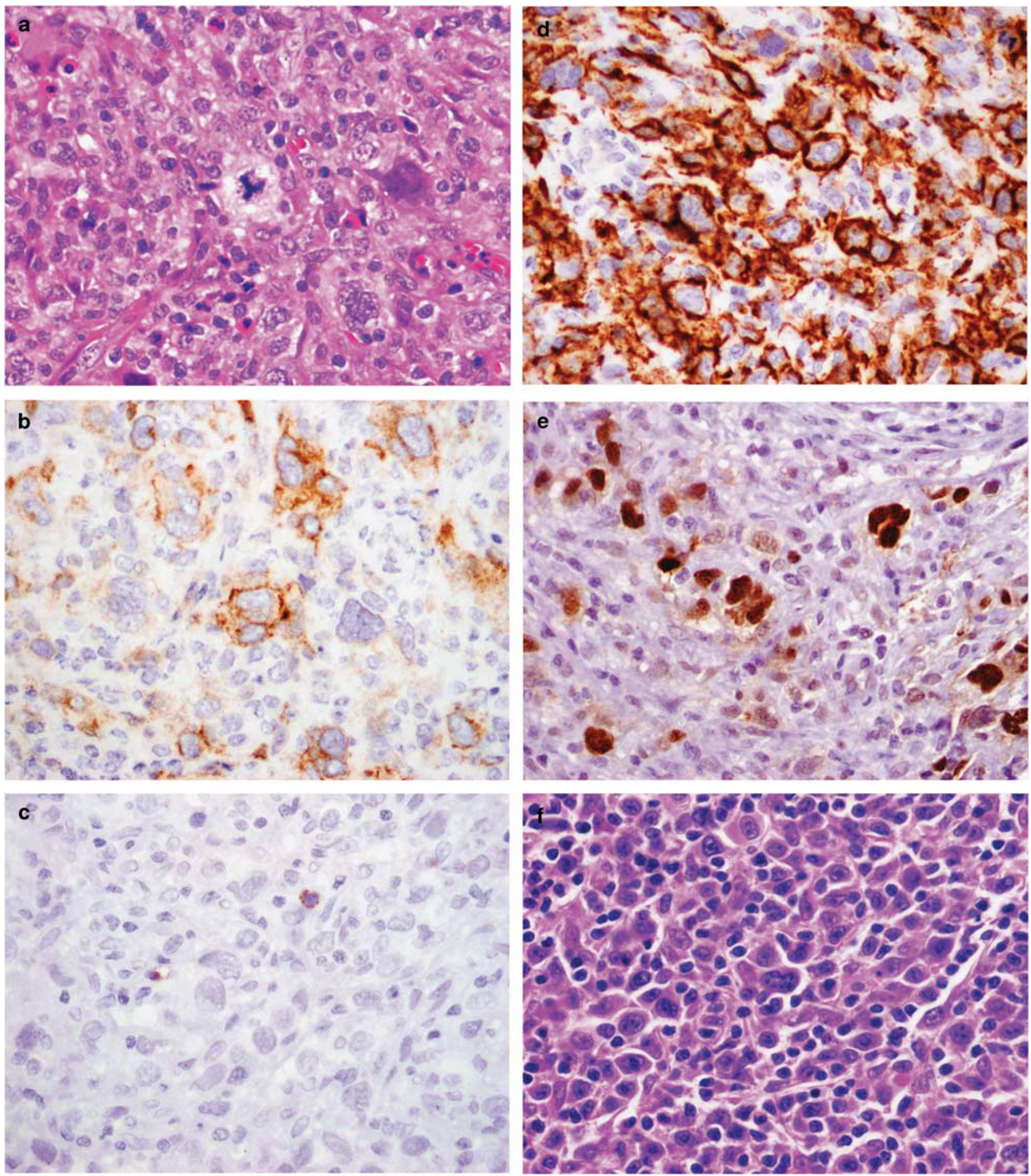

Figure 1 Morphological and immunophenotypic features of gray zone lymphoma. Gray zone lymphoma with morphologic features of classical Hodgkin's lymphoma and immunophenotypic features of primary mediastinal large B-cell lymphoma (case no. 5; left hand panels). Characteristic Hodgkin-Reed-Sternberg cells in an inflammatory background with numerous eosinophils (H\&E) (a). Tumor cells are partially positive for CD30 (b), negative for CD15 (c), and positive for CD20 (d) and Cyclin E (e). Gray zone lymphoma with morphologic features of primary mediastinal large B-cell lymphoma and immunophenotypic features of classical Hodkgin's lymphoma (case no. 20; right hand panels). Sheets of relatively monomorphic large tumor cells with abundant pale cytoplasm (H\&E) (f). Tumor cells are positive for CD30 (g) and CD15 (h), but are negative for CD20 (i) and Cyclin E (j) (original magnification $\mathbf{a}-\mathbf{j}: \times 40$ ). 

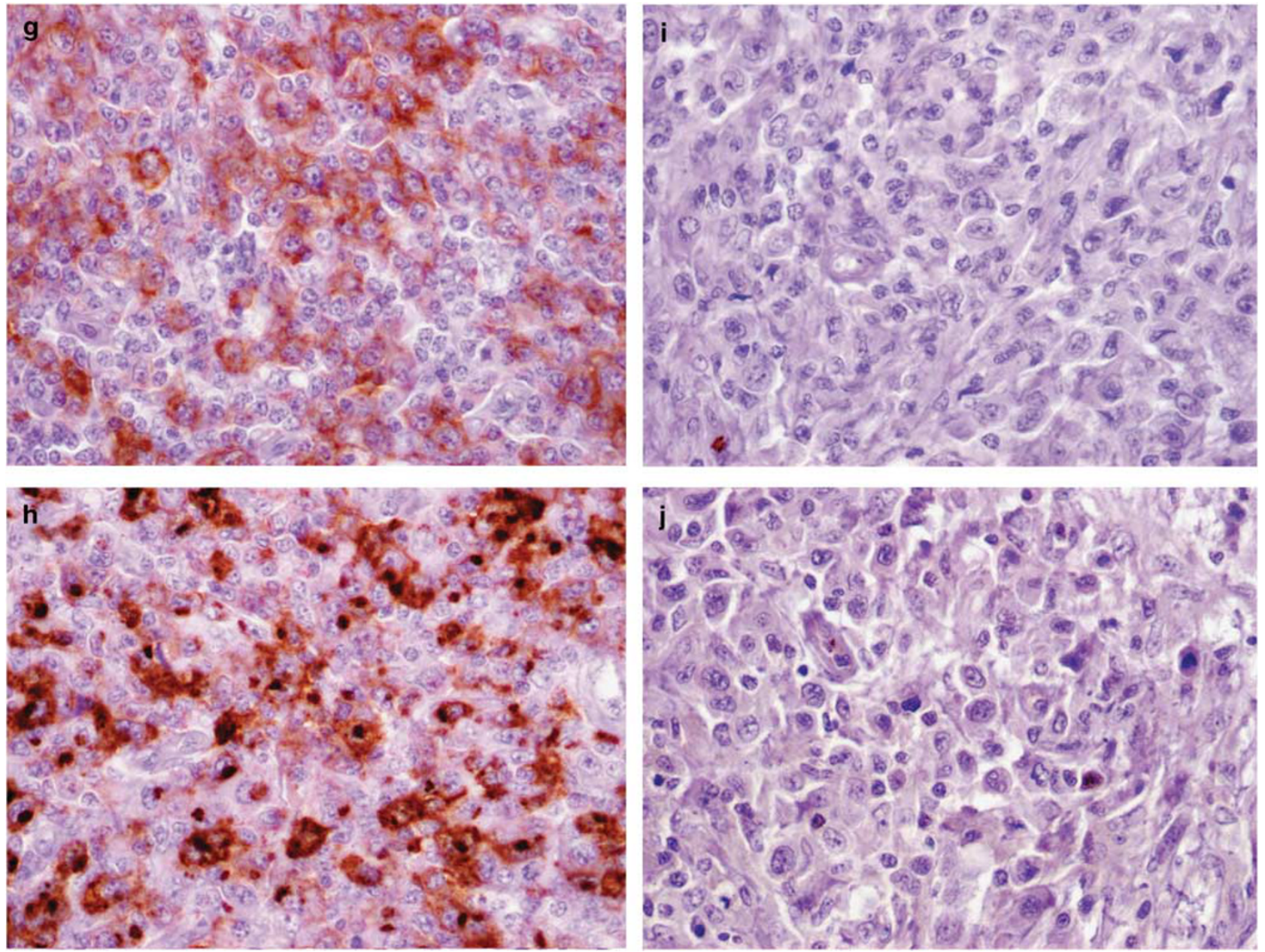

Figure 1 Continued.

indicated a clonal relationship between the two histologically discordant lymphomas (Figure 2).

\section{Fluorescence In Situ Hybridization}

Interphase FISH studies were performed for the gene loci of BCL11 and REL (2p16.1), MYC (8q24), JAK2 and PDL2 (9p24.1) and CIITA (16p13.13) in tissue microarray and whole tissue sections. Thirty-three cases were available for FISH studies. The mediastinal synchronous/metachronous lymphoma cases comprised two biopsies per case, one biopsy of classical Hodgkin's lymphoma and another of primary mediastinal large B-cell lymphoma. However, for cases no. 31 and 33, no material was available from the first biopsy of each case. Thirty cases $(30 / 33,91 \%)$ and 26 cases $(26 / 33,79 \%)$ could be analyzed for $2 \mathrm{p} 16.1$ and $8 \mathrm{q} 24$, respectively. Additional copies of 2 p16.1 including gains $(n=6)$ and amplifications $(n=4)$ were detected in 10 cases $(10 / 30,33 \%)$, being more common in cases resembling classical Hodgkin's lymphoma (Tables 3 and 4, Figure 3). Signal patterns indicating breakpoints affecting the $M Y C$ locus in $8 \mathrm{q} 24$ were not observed in any of the cases, but seven biopsies (7/26, 27\%) contained a significant number of cells with signal patterns indicating a gain of the MYC locus. FISH analysis for 9p24.1 and 16p13.13 could be performed successfully in 31/33 cases (94\%) and 30/33 cases (91\%), respectively. Additional copies of 9p24.1 including gains or amplifications were observed in 17/31 cases (55\%), being more common in cases with large-B-cell-like morphology (Tables 3 and 4). Of note, one of the cases showed a signal constellation indicating a chromosomal breakpoint in 9p24.1, in addition to a gain (no. 31). With the probes targeting the CIITA locus at 16p13.13, we found signal patterns indicating a break in eight cases $(8 / 30,27 \%)$, and amplification in two cases $(2 / 30,7 \%)$. One case carried a gain $(1 / 30,3 \%)$ (Figure 3). Interestingly, one case of mediastinal metachronous lymphoma (no. 32) carried a gain in 9p24.1 as well as a break in 16p13.13 in both the Hodgkin's lymphoma and the primary mediastinal large B-cell lymphoma, indicative of a clonal relationship. Two cases showed gains, amplifications or breaks for all four loci investigated (no. 6, no. 22) (Table 4). 

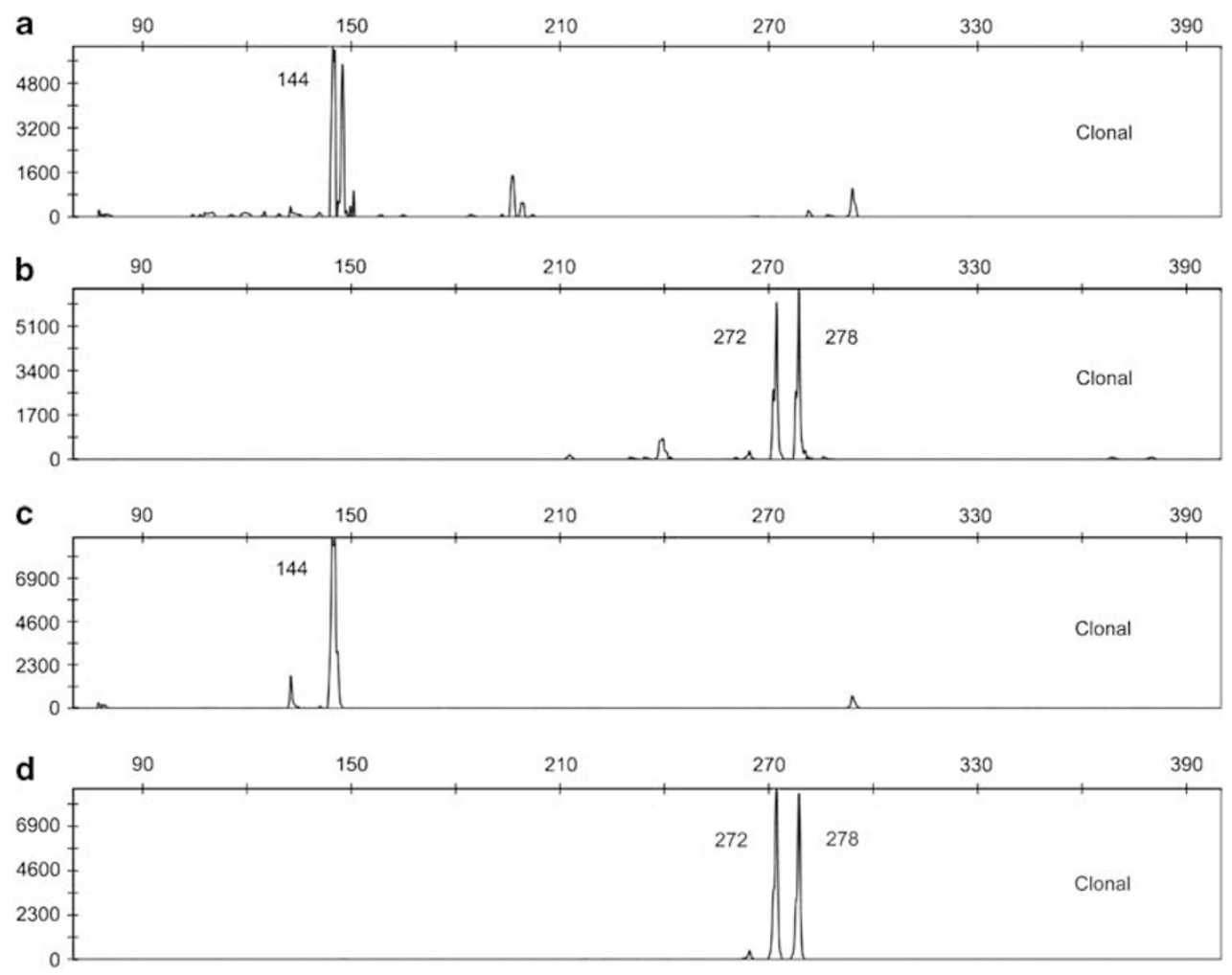

Figure 2 Immunoglobulin gene rearrangement studies for kappa loci in both lymphomas, classical Hodgkin's lymphoma (a, b) and primary mediastinal large B-cell lymphoma (c, d) of a mediastinal metachronous lymphoma (no. 32). Clonal peaks of identical size were detected in both tube A (a, c) and tube B (b, d) from both specimens examined. Peaks were seen at $144 \mathrm{bp}$ in tube A, and $272 \mathrm{bp}$ and $278 \mathrm{bp}$ in tube B. This result implies a clonal relationship between the classical Hodgkin's lymphoma and the primary mediastinal large B-cell lymphoma. No significant peaks were detected for the IGH locus (data not shown).

To determine the association between the different genetic alterations with the presence of mediastinal disease Fisher's exact test was performed. The analyses showed that cases with mediastinal disease presented more frequently with alterations at the investigated gene loci in 2p16.1, 8q24 and 9p24.1, whereas alterations involving 16p13.13 were more common in cases without evident mediastinal disease (Table 2). A similar analysis was performed for associations between the presence of different genetic alterations and the morphology of the gray zone lymphoma cases (Hodgkin-like or large-B-cell-lymphoma-like). We found that gains/amplifications in 2p16.1 were more common in cases with Hodgkin-like morphology, whereas gains/amplifications in 9p24.1 were more frequent in cases with large-B-cell-lymphoma-morphology (Table 3). However, these findings did not reach statistical significance.

Downregulation of surface HLA class II expression has been described as one of the functional consequences of CIITA gene fusions. ${ }^{23}$ Therefore, we determined the association of our results for CIITA rearrangement observed by FISH with HLA-DR expression. In our series we did not find a significant association between CIITA gene fusions and reduced HLA class II expression $(P=0.36$, Fisher's exact test). In most cases with CIITA rearrangement we also observed expression of HLA-DR by immunohistochemistry (Tables 1 and 4).

\section{Discussion}

B-cell lymphoma, unclassifiable, with features intermediate between diffuse large B-cell lymphoma and classical Hodgkin's lymphoma, more conveniently termed gray zone lymphoma, designates a variant of lymphoma combining features of Hodgkin's lymphoma and large B-cell lymphoma, but not readily assigned to either category. There are no published data on recurrent genetic aberrations in these tumors. Such data would help in the definition of gray zone lymphoma, and might determine if these cases are more closely related to either one of the parent entities, or manifest distinctive features of their own. Such data also might be of value in selecting therapy for this clinically aggressive lymphoma subtype. Here we present the first study of chromosomal aberrations in a series of gray zone lymphoma. Furthermore, we compare those cases with evident mediastinal involvement to cases with similar morphology and immunophenotype, in which mediastinal involvement appears to be absent based on available data. 
Table 4 Genetic characteristics of non-mediastinal (1-9) and mediastinal (10-33) cases

\begin{tabular}{|c|c|c|c|c|c|}
\hline No & Diagnosis & $2 p 16.1$ & $8 q 24$ & $9 p 24.1$ & $16 p 13.13$ \\
\hline 1 & GZL & WT & WT & WT & WT \\
\hline $2^{\mathrm{a}}$ & GZL & WT & WT & WT & A \\
\hline 3 & GZL & WT & nc & WT & WT \\
\hline 4 & GZL & A & WT & WT & WT \\
\hline 5 & GZL & WT & WT & A & B \\
\hline 6 & GZL & G & G & A & B \\
\hline 7 & GZL & WT & WT & A & WT \\
\hline 8 & GZL & $\mathrm{nc}$ & $\mathrm{nc}$ & nc & WT \\
\hline 9 & GZL & WT & nc & WT & $\mathrm{B}$ \\
\hline 10 & GZL & WT & WT & WT & WT \\
\hline $11^{\mathrm{b}}$ & GZL & $\mathrm{G}$ & G & G & WT \\
\hline $12^{\mathrm{a}}$ & GZL & G & WT & A & B \\
\hline 13 & GZL & A & WT & WT & WT \\
\hline 14 & GZL & WT & WT & WT & WT \\
\hline 15 & GZL & WT & $\mathrm{nc}$ & $\mathrm{G}$ & G \\
\hline 16 & GZL & WT & WT & $\mathrm{A}$ & WT \\
\hline $17^{\mathrm{b}}$ & GZL & WT & $\mathrm{G}$ & WT & nc \\
\hline 18 & GZL & A & WT & WT & WT \\
\hline $19^{\mathrm{a}}$ & GZL & WT & WT & A & B \\
\hline 20 & GZL & WT & WT & $\mathrm{G}$ & B \\
\hline 21 & GZL & WT & WT & WT & WT \\
\hline $22^{\mathrm{a}}$ & GZL & $\mathrm{G}$ & G & G & A \\
\hline 23 & GZL & WT & WT & WT & WT \\
\hline 24 & GZL & G & G & A & WT \\
\hline $25^{\mathrm{b}}$ & GZL & A & WT & WT & WT \\
\hline $26^{\mathrm{b}}$ & GZL & WT & G & G & WT \\
\hline 27 & GZL & WT & WT & A & B \\
\hline $28^{\mathrm{c}}$ & CHL/PMBL & WT & $\mathrm{nc}$ & A & WT \\
\hline $29^{\mathrm{c}}$ & CHL/PMBL & $\mathrm{nc}$ & $\mathrm{nc}$ & $\mathrm{nc}$ & nc \\
\hline $30^{\mathrm{a}}$ & CHL/PMBL & WT & nc & WT & nc \\
\hline \multirow[t]{2}{*}{$31^{\mathrm{c}}$} & $\mathrm{CHL}^{\mathrm{d}}$ & nd & nd & nd & nd \\
\hline & $\mathrm{PMBL}^{\mathrm{d}}$ & G & WT & G/B & WT \\
\hline \multirow[t]{2}{*}{32} & $\mathrm{CHL}^{\mathrm{d}}$ & nc & WT & G & B \\
\hline & $\mathrm{PMBL}^{\mathrm{d}}$ & WT & G & G & B \\
\hline \multirow[t]{2}{*}{$33^{\mathrm{b}}$} & $\mathrm{PMBL}^{\mathrm{e}}$ & nd & nd & nd & nd \\
\hline & $\mathrm{CHL}^{\mathrm{e}}$ & nc & WT & G & WT \\
\hline
\end{tabular}

Abbreviations: A, amplification (ie $>4$ copies or cloud); B, break; CHL, classical Hodgkin's lymphoma; G, gain (ie 3-4 copies); GZL, gray zone lymphoma; nc, non contributory; nd, not done; No, case number; PMBL, primary mediastinal large B-cell lymphoma; WT, wildtype (ie 2 copies).

${ }^{\mathrm{a}}$ Patient was part of the study by Eberle et al. ${ }^{25}$

${ }^{\mathrm{b}}$ Patient was part of the study by Traverse-Glehen et al. ${ }^{6}$

${ }^{\mathrm{C}}$ Patient was part of the study by Traverse-Glehen et al ${ }^{6}$ and Eberle et al. ${ }^{25}$ ${ }^{\mathrm{d}} \mathrm{CHL}$ with relapse as PMBL.

${ }^{\mathrm{e}} \mathrm{PMBL}$ with relapse as CHL.

As gray zone lymphomas demonstrate morphological and immunophenotypic features intermediate between primary mediastinal large B-cell lymphoma and classical Hodgkin's lymphoma we focused on genetic aberrations previously described for the related parent entities. Genetic aberrations involving $2 p$ and $9 p$ have been frequently detected in cases of classical Hodgkin's lymphoma and primary mediastinal large B-cell lymphoma. ${ }^{11-22}$ We identified gains or amplifications of 2 p16.1 in $33 \%$ of gray zone lymphoma, with a slightly higher frequency in cases with Hodgkin-like morphology (42\%) as compared with gray zone lymphomas with largeB-cell-like morphology (29\%). Similarly, the FISH
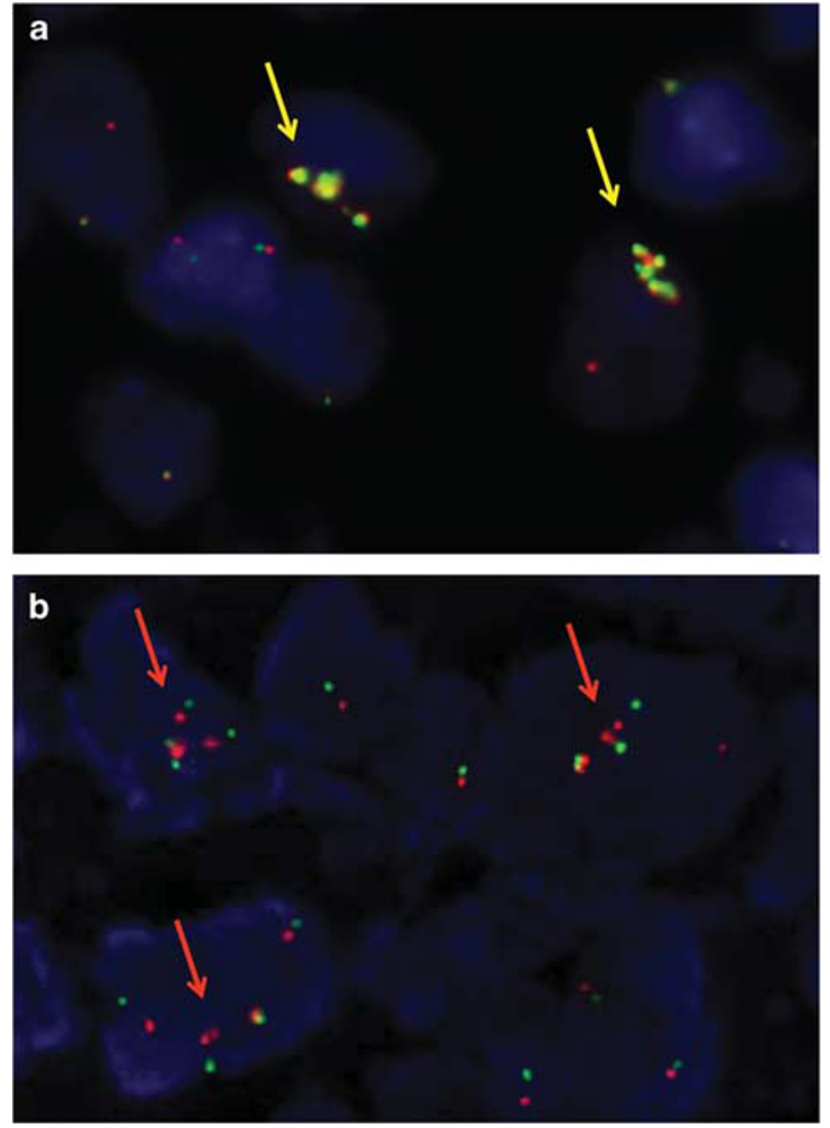

Figure 3 Representative results of interphase FISH analysis for detection of chromosomal imbalances or rearrangements involving the gene loci of $R E L / B C L 11 A$ (2p16) (a) and CIITA (16p13.13) (b) in cases of gray zone lymphoma. Detection of multiple signals indicating amplification of 2p16 (a, yellow arrows, case 18) and detection of red and green break-apart signals indicating a chromosomal breakpoint affecting the CIITA locus in 16p13.13 (b, red arrows, case 27).

results for gains/amplifications of 9p24.1 (55\%) harboring the gene loci of JAK2, PDL1 and PDL2 closely approach the results reported for primary mediastinal large B-cell lymphoma, ${ }^{11,14,19,21}$ with a rate higher than that typically observed in classical Hodgkin's lymphoma, ${ }^{12,13,17,20,22}$ even if one restricts the analysis to the nodular sclerosis subtype of classical Hodgkin's lymphoma. 9p alterations were more common in cases of gray zone lymphoma with large-B-cell-like morphology $(57 \%)$ as compared with gray zone lymphomas with Hodgkin-like morphology $(42 \%)$. In 2003, Rosenwald et $a l^{8}$ described PDL2 as highly expressed in both primary mediastinal large B-cell lymphoma and classical Hodgkin's lymphoma, and the genomic loci for $P D L 2$ and neighboring genes were amplified in more than half of the primary mediastinal large B-cell lymphomas and also in Hodgkin's lymphoma cell lines. A more recent study by Green et $a 2^{29}$ identified the PD-1 ligands as key targets of the 9p24.1 amplification in classical Hodgkin's lymphoma and primary mediastinal large B-cell lymphoma 
and showed that $J A K 2$ further augments PD-1 ligand expression in these tumors. Gains/amplifications in 9p24.1 in more than half of the cases of our study cohort suggest that this pathway is also likely to be important in gray zone lymphoma pathogenesis.

A recent study of genetic features of primary mediastinal large B-cell lymphoma in children investigated chromosomal aberrations for $2 \mathrm{p} 16.1$, 9p24.1 and 8q24, and found similar frequencies for primary mediastinal large B-cell lymphoma in children as compared with adults. ${ }^{21}$ Pediatric primary mediastinal large B-cell lymphomas showed signal patterns indicating gains or amplifications of 2p16.1 and 9p24.1 in 41 and 59\% of cases, respectively. Furthermore, four cases $(27 \%)$ of pediatric primary mediastinal large B-cell lymphoma carried aberrations for 8q24. Interestingly, those authors identified one case of gray zone lymphoma accessible for genetic studies, but it did not reveal any alterations at 2 p16.1, 9p24.1 or $8 q 24 . .^{21}$ In our study cohort the incidence of alterations affecting the $M Y C$ locus in $8 \mathrm{q} 24(27 \%)$ is similar to that observed in primary mediastinal large B-cell lymphoma, ${ }^{21}$ and does not help to explain the greater clinical aggressiveness in gray zone lymphoma, as compared with primary mediastinal large B-cell lymphoma.

Rearrangements involving 16p have been described in the literature in cases of classical Hodgkin's lymphoma. ${ }^{13,16,17,22}$ A recent study by Steidl et $a l^{23}$ evaluated 263 B-cell lymphomas for chromosomal rearrangements involving the MHC class II transactivator CIITA (16p13.13). Interestingly, they could demonstrate recurrent rearrangement in primary mediastinal large B-cell lymphoma (29/77, 38\%) and classical Hodgkin's lymphoma (8/55, 15\%), whereas rearrangement of this locus was only present in 4/131 cases of diffuse large B-cell lymphoma (4\%). In the current study we detected breaks in $27 \%$ (8/30), a frequency intermediate between that observed for classical Hodgkin's lymphoma and primary mediastinal large B-cell lymphoma. It has been postulated that breaks involving CIITA might facilitate escape from immune surveillance of the tumor cells through various mechanisms. One of these mechanisms was described as downregulation of HLA-class II associated molecules secondary to CIITA gene fusions. ${ }^{23}$ The absence of an association between CIITA gene rearrangement and reduced HLA-DR expression in our study cohort suggests that other mechanisms might have a role in gray zone lymphoma such as overexpression of CIITA fusion partners or other genetic alterations affecting the 16 p13.13 locus. Further molecular studies are needed to characterize CIITA rearrangements and their functional consequences in this lymphoma entity.

Although the majority of our study patients (73\%) presented with mediastinal disease, there was a subset with similar immunohistological features without evident mediastinal involvement. Categor- ization was based on clinical data at presentation obtained from referring physicians. In this series of cases largely referred in consultation, uniform imaging data were not available in all cases. Nevertheless, there was a statistically significant difference in age at presentation (29.5 years vs 55 years, $P=0.017$ ) in patients with and without mediastinal disease, suggesting underlying differences in biology. Looking at the genetic loci, tumors in patients with mediastinal disease more frequently exhibited alterations in the 2p16.1, 9p24.1 and 8q24 loci, whereas tumors from patients without evident mediastinal disease had a higher incidence of aberrations at 16p13.13. However, these differences did not attain statistical significance. For the time being this result supports the inclusion of both groups in 'B-cell lymphoma, unclassifiable, with features intermediate between diffuse large B-cell lymphoma and classical Hodgkin lymphoma'.

Primary mediastinal large B-cell lymphoma and classical Hodgkin's lymphoma, nodular sclerosis subtype, share a number of common clinical features. Gray zone lymphomas have a similar clinical presentation, but in contrast to the parent entities, appear to be more common in males than females. ${ }^{5,6}$ Our study cohort was also characterized by a male predominance (a male to female ratio of 20:13). The median age at presentation was 32 years, although as noted above patients with mediastinal disease at presentation were younger.

We attempted to subclassify our cases of gray zone lymphoma based on the appearance of the tumor on H\&E-stained sections as more closely resembling either classical Hodgkin's lymphoma or primary mediastinal large B-cell lymphoma. Such a subdivision was not straightforward, and in most cases there were variations in morphology and immunophenotype that placed these tumors in an intermediate group. Other than CD30, which was positive in the vast majority of cases, Oct.2 and BOB.1 were usually expressed, regardless of other immunophenotypic or morphological features. A recent study by Hoeller et $a l^{30}$ investigated further immunohistochemical markers that might be helpful in distinguishing between primary mediastinal large B-cell lymphoma and classical Hodgkin's lymphoma, and suggested that an investigation of gray zone lymphomas with Cyclin E and p63 might prove useful. They proposed a positive predictive value and high sensitivity of p63 for primary mediastinal large B-cell lymphoma and Cyclin E for classical Hodgkin's lymphoma. We did not find these markers to be helpful in further characterizing our series of gray zone lymphoma. Eighty-five percent of the cases were positive for Cyclin E, including all but one case with large-B-cell-morphology (93\%). Similarly, more than half of our gray zone lymphoma cases with large-B-cell-like morphology expressed p63 (8/15), but similar levels of expression were seen in cases with Hodgkin-like morphology (50\%). Therefore, p63 and Cyclin E did 
not help to differentiate our series of gray zone lymphomas into more well-defined diagnostic categories, such as primary mediastinal large B-cell lymphoma or classical Hodgkin's lymphoma. Thus, a characteristic and unifying feature of gray zone lymphomas was that gray zone lymphomas cannot be clearly assigned to any of the parent entities, and continue to fall in the gray zone. A similar conclusion was reached in an analysis of gray zone lymphomas utilizing large-scale methylation profiling. ${ }^{25}$

The existence of mediastinal composite and mediastinal synchronous/metachronous lymphomas comprising large B-cell lymphoma and Hodgkin's lymphoma in the same patient underscores the immunohistological plasticity of the neoplastic clone. ${ }^{6}$ Not unexpectedly, the genetic aberrations in this group were similar to those of the other gray zone lymphomas. In line with previous findings, ${ }^{6}$ we could demonstrate a clonal relationship between classical Hodgkin's lymphoma and primary mediastinal large B-cell lymphoma diagnosed sequentially in the same patient (no. 32). Of note, a gain for 9p24.1 and a break for 16p13.13 were also observed in both biopsies of this patient, further supporting a clonal relationship, and suggesting that neither of these aberrations was acquired secondarily.

In summary, our studies reveal further insights into the pathogenesis of gray zone lymphoma. Our results show that there are a number of common immunophenotypic features and genetic alterations that link gray zone lymphoma, classical Hodgkin's lymphoma and primary mediastinal large B-cell lymphoma, further underscoring their close relationship. However, based on our findings, a clear association of gray zone lymphoma to either one of the parent entities could not be observed. Interestingly, we also identified some of the same aberrations in a subset of gray zone lymphomas in patients without evident mediastinal disease, for the time being justifying both groups in 'B-cell lymphoma, unclassifiable, with features intermediate between diffuse large B-cell lymphoma and classical Hodgkin lymphoma'.

\section{Acknowledgements}

This work was supported by the intramural program of the Center for Cancer Research, National Cancer Institute, NIH and by the Deutsche Krebshilfe (grant \# 107748). IS is supported by the Alexander von Humboldt Foundation. CS is supported by the Cancer Research Society Steven E Drabin Fellowship, the Michael Smith Foundation for Health Research and the Lymphoma Research Foundation. RDG received operational funds from the Canadian Institutes of Health Research (CIHR, grant \# 178536). We gratefully acknowledge the excellent support of Reina Zühlke-Jenisch, Theresa Davies-Hill, Silke Williams, Nicole Grant, Thu Anh Pham, Trinh Hoc-Tran Pham, Winnifred Navarro, Seth Steinberg and Kamran Ghoreschi.

\section{Disclosure/conflict of interest}

The authors declare no conflict of interest.

\section{References}

1 Perrone T, Frizzera G, Rosai J. Mediastinal diffuse large-cell lymphoma with sclerosis. A clinicopathologic study of 60 cases. Am J Surg Pathol 1986;10: 176-191.

2 Gonzalez CL, Medeiros LJ, Jaffe ES. Composite lymphoma. A clinicopathologic analysis of nine patients with Hodgkin's disease and B-cell non-Hodgkin's lymphoma. Am J Clin Pathol 1991;96:81-89.

3 Zarate-Osorno A, Medeiros LJ, Longo DL, et al. NonHodgkin's lymphomas arising in patients successfully treated for Hodgkin's disease. A clinical, histologic, and immunophenotypic study of 14 cases. Am J Surg Pathol 1992;16:885-895.

4 Zarate-Osorno A, Medeiros LJ, Kingma DW, et al. Hodgkin's disease following non-Hodgkin's lymphoma. A clinicopathologic and immunophenotypic study of nine cases. Am J Surg Pathol 1993;17:123-132.

5 Garcia JF, Mollejo M, Fraga M, et al. Large B-cell lymphoma with Hodgkin's features. Histopathology 2005;47:101-110.

6 Traverse-Glehen A, Pittaluga S, Gaulard P, et al. Mediastinal gray zone lymphoma: the missing link between classic hodgkin's lymphoma and mediastinal large B-cell lymphoma. Am J Surg Pathol 2005;29: 1411-1421.

7 Savage KJ, Monti S, Kutok JL, et al. The molecular signature of mediastinal large B-cell lymphoma differs from that of other diffuse large B-cell lymphomas and shares features with classical Hodgkin lymphoma. Blood 2003;102:3871-3879.

8 Rosenwald A, Wright G, Leroy K, et al. Molecular diagnosis of primary mediastinal B cell lymphoma identifies a clinically favorable subgroup of diffuse large B cell lymphoma related to Hodgkin lymphoma. J Exp Med 2003;198:851-862.

9 Calvo KR, Traverse-Glehen A, Pittaluga S, et al. Molecular profiling provides evidence of primary mediastinal large B-cell lymphoma as a distinct entity related to classic hodgkin lymphoma: implications for mediastinal gray zone lymphomas as an intermediate form of B-cell lymphoma. Adv Anat Pathol 2004;11: $227-238$.

10 Jaffe ES, Stein H, Swerdlow SH, et al. B-cell lymphoma, unclassifiable, with features intermediate between diffuse large B-cell lymphoma and classical Hodgkin lymphoma. In: Swerdlow SH, Campo E, Harris NL, et al (eds). WHO Classification of Tumours of Haematopoietic and Lymphoid Tissues, 4th edn. International Agency for Research on Cancer: Lyon, 2008, pp. 267-268.

11 Joos S, Otano-Joos MI, Ziegler S, et al. Primary mediastinal (thymic) B-cell lymphoma is characterized by gains of chromosomal material including $9 p$ and amplification of the REL gene. Blood 1996;87: 1571-1578.

12 Joos S, Kupper M, Ohl S, et al. Genomic imbalances including amplification of the tyrosine kinase gene JAK2 in CD30+ Hodgkin cells. Cancer Res 2000;60: 549-552. 
13 Joos S, Menz CK, Wrobel G, et al. Classical Hodgkin lymphoma is characterized by recurrent copy number gains of the short arm of chromosome 2. Blood 2002; 99:1381-1387.

14 Bentz M, Barth TF, Bruderlein S, et al. Gain of chromosome arm $9 \mathrm{p}$ is characteristic of primary mediastinal B-cell lymphoma (MBL): comprehensive molecular cytogenetic analysis and presentation of a novel MBL cell line. Genes Chromosomes Cancer 2001;30:393-401.

15 Martin-Subero JI, Gesk S, Harder L, et al. Recurrent involvement of the REL and BCL11A loci in classical Hodgkin lymphoma. Blood 2002;99:1474-1477.

16 Martin-Subero JI, Klapper W, Sotnikova A, et al. Chromosomal breakpoints affecting immunoglobulin loci are recurrent in Hodgkin and Reed-Sternberg cells of classical Hodgkin lymphoma. Cancer Res 2006;66: 10332-10338.

17 Chui DT, Hammond D, Baird M, et al. Classical Hodgkin lymphoma is associated with frequent gains of 17q. Genes Chromosomes Cancer 2003;38:126-136.

18 Weniger MA, Pulford K, Gesk S, et al. Gains of the proto-oncogene BCL11A and nuclear accumulation of BCL11A(XL) protein are frequent in primary mediastinal B-cell lymphoma. Leukemia 2006;20:1880-1882.

19 Wessendorf S, Barth TF, Viardot A, et al. Further delineation of chromosomal consensus regions in primary mediastinal B-cell lymphomas: an analysis of 37 tumor samples using high-resolution genomic profiling (array-CGH). Leukemia 2007;21:2463-2469.

20 Hartmann S, Martin-Subero JI, Gesk S, et al. Detection of genomic imbalances in microdissected Hodgkin and Reed-Sternberg cells of classical Hodgkin's lymphoma by array-based comparative genomic hybridization. Haematologica 2008;93:1318-1326.

21 Oschlies I, Burkhardt B, Salaverria I, et al. Clinical, pathological and genetic features of primary mediastinal large B-cell lymphomas and mediastinal gray zone lymphomas in children. Haematologica 2011;96: 262-268.

22 Steidl C, Telenius A, Shah SP, et al. Genome-wide copy number analysis of Hodgkin Reed-Sternberg cells identifies recurrent imbalances with correlations to treatment outcome. Blood 2010;116:418-427.

23 Steidl C, Shah SP, Woolcock BW, et al. MHC class II transactivator CIITA is a recurrent gene fusion partner in lymphoid cancers. Nature 2011; 471:377-381.

24 Campo E, Swerdlow SH, Harris NL, et al. The 2008 WHO classification of lymphoid neoplasms and beyond: evolving concepts and practical applications. Blood 2011;117:5019-5032.

25 Eberle FC, Rodriguez-Canales J, Wei L, et al. Methylation profiling of mediastinal gray zone lymphoma reveals a distinctive signature with elements shared by classical Hodgkin's lymphoma and primary mediastinal large B-cell lymphoma. Haematologica 2011;96: $558-566$.

26 Ramasamy I, Brisco M, Morley A. Improved PCR method for detecting monoclonal immunoglobulin heavy chain rearrangement in B cell neoplasms. J Clin Pathol 1992;45:770-775.

27 van Dongen JJ, Langerak AW, Bruggemann M, et al. Design and standardization of PCR primers and protocols for detection of clonal immunoglobulin and T-cell receptor gene recombinations in suspect lymphoproliferations: report of the BIOMED-2 concerted action BMH4-CT98-3936. Leukemia 2003;17: 2257-2317.

28 Ventura RA, Martin-Subero JI, Jones M, et al. FISH analysis for the detection of lymphoma-associated chromosomal abnormalities in routine paraffin-embedded tissue. J Mol Diagn 2006;8:141-151.

29 Green MR, Monti S, Rodig SJ, et al. Integrative analysis reveals selective 9p24.1 amplification, increased PD-1 ligand expression, and further induction via JAK2 in nodular sclerosing Hodgkin lymphoma and primary mediastinal large B-cell lymphoma. Blood 2010;116: 3268-3277.

30 Hoeller S, Zihler D, Zlobec I, et al. BOB.1, CD79a and cyclin $\mathrm{E}$ are the most appropriate markers to discriminate classical Hodgkin's lymphoma from primary mediastinal large B-cell lymphoma. Histopathology 2010;56:217-228.

Supplementary Information accompanies the paper on Modern Pathology website (http://www.nature.com/ modpathol) 